\title{
AGO Recommendations for the Diagnosis and Treatment of Patients with Early Breast Cancer: Update 2021
}

\author{
Nina Ditsch ${ }^{a}$ Cornelia Kolberg-Liedtke ${ }^{b}$ Michael Friedrich ${ }^{c}$ Christian Jackisch ${ }^{d}$ \\ Ute-Susann Albert ${ }^{\mathrm{e}}$ Maggie Banys-Paluchowski ${ }^{\mathrm{f}} \mathrm{g}$ Ingo Bauerfeind ${ }^{\mathrm{h}}$ Jens-Uwe Blohmer ${ }^{\mathrm{i}}$ \\ Wilfried Budach ${ }^{j}$ Peter Dall ${ }^{k} \quad$ Eva M. Fallenberg' Peter A. Fasching ${ }^{\mathrm{m}}$ Tanja Fehm ${ }^{\mathrm{n}}$ \\ Bernd Gerber $^{\circ}$ Oleg Gluz ${ }^{p}$ Nadia Harbeck ${ }^{q}$ Jörg Heil ${ }^{r}$ Jens Huober ${ }^{s}$ Hans-Heinrich Kreipe ${ }^{t}$
} David Krug ${ }^{u}$ Thorsten Kühn ${ }^{v}$ Sherko Kümmelw Sibylle Loibl ${ }^{\mathrm{x}}$ Diana Lüftner ${ }^{\mathrm{y}}$ Michael P. Lux ${ }^{z}$ Nicolai Maass ${ }^{A} \quad$ Christoph Mundhenke $^{B} \quad$ Ulrike Nitz $^{p}$ Tjoung-Won Park-Simon ${ }^{C}$ Toralf Reimer ${ }^{\circ}$ Kerstin Rhiem ${ }^{D}$ Achim Rody ${ }^{f}$ Marcus Schmidt ${ }^{E}$ Andreas Schneeweiss ${ }^{F}$ Florian Schütz ${ }^{G}$ Hans-Peter Sinn ${ }^{H}$ Christine Solbach ${ }^{J}$ Erich-Franz Solomayer $^{\mathrm{K}}$ Elmar Stickeler ${ }^{\mathrm{L}}$ Christoph Thomssen ${ }^{\mathrm{M}}$ Michael Untch $^{\mathrm{N}}$ Isabell Witzel ${ }^{\mathrm{O}}$ Achim Wöckel $^{\mathrm{e}}$ Volkmar Müller $^{\mathrm{O}}$ Wolfgang Janni ${ }^{\mathrm{P}}$ Marc Thill ${ }^{\mathrm{Q}}$

${ }^{a}$ Klinik für Frauenheilkunde und Geburtshilfe, Universitätsklinikum Augsburg, Augsburg, Germany; ${ }^{\text {bKlinik für }}$ Frauenheilkunde und Geburtshilfe, Universitätsklinikum Essen, Essen, Germany; ${ }^{C}$ Klinik für Frauenheilkunde und

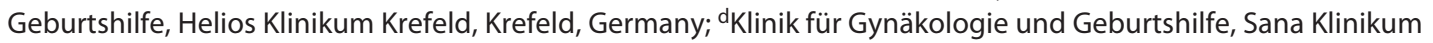

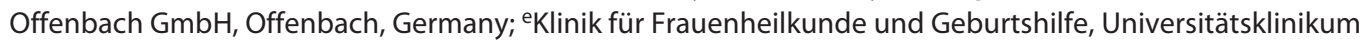

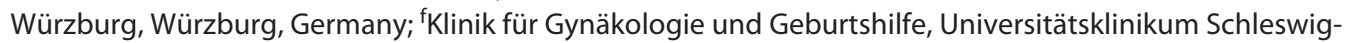
Holstein, Campus Lübeck, Lübeck, Germany; ${ }^{9}$ Medizinische Fakultät, Heinrich-Heine-Universität Düsseldorf, Düsseldorf, Germany; ${ }^{\text {} F r a u e n k l i n i k, ~ K l i n i k u m ~ L a n d s h u t ~ g e m e i n n u ̈ t z i g e ~ G m b H, ~ L a n d s h u t, ~ G e r m a n y ; ~ ' K l i n i k ~ f u ̈ r ~}$ Gynäkologie mit Brustzentrum des Universitätsklinikums der Charité, Berlin, Germany; 'Strahlentherapie, Radiologie Düsseldorf, Universitätsklinikum Düsseldorf, Düsseldorf, Germany; ${ }^{k}$ Frauenklinik, Städtisches Klinikum Lüneburg, Lüneburg, Germany; Institut für klinische Radiologie, Klinikum der Universität München, Campus Großhadern, Munich, Germany; ${ }^{\mathrm{m}}$ Frauenklinik, Universitätsklinikum Erlangen, Erlangen, Germany; ${ }^{\mathrm{n}}$ Klinik für Gynäkologie und Geburtshilfe, Universitätsklinikum Düsseldorf, Düsseldorf, Germany; Universitätsfrauenklinik und Poliklinik am

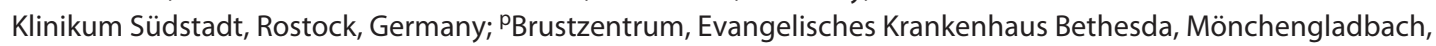
Germany; ${ }^{9 B}$ rustzentrum, Klinik für Gynäkologie und Geburtshilfe, Klinikum der Ludwig-Maximilians-Universität,

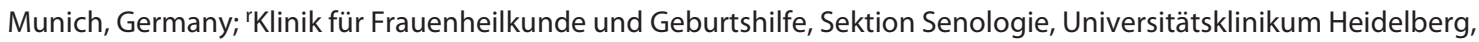

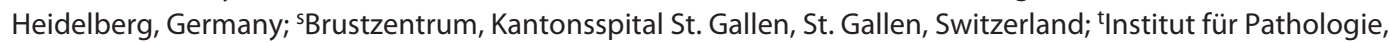

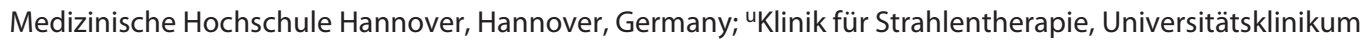
Schleswig-Holstein, Campus Kiel, Kiel, Germany; "Klinik für Frauenheilkunde und Geburtshilfe, Klinikum Esslingen,

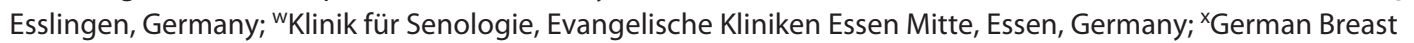

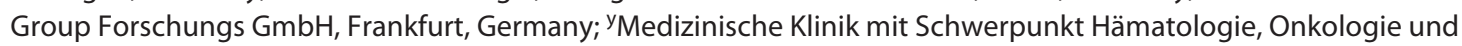
Tumorimmunologie, Charité, Berlin, Germany; ${ }^{2}$ Kooperatives Brustzentrum Paderborn, Klinik für Gynäkologie und Geburtshilfe, Frauenklinik St. Louise, Paderborn und St. Josefs-Krankenhaus, Salzkotten, St. Vincenz-Krankenhaus $\mathrm{GmbH}$, Paderborn, Germany; ${ }^{A}$ Klinik für Gynäkologie und Geburtshilfe, Universitätsklinikum Schleswig-Holstein, Campus Kiel, Kiel, Germany; ${ }^{B}$ Klinik für Gynäkologie und Geburtshilfe, Klinikum Bayreuth, Bayreuth, Germany; ${ }^{C_{K}}$ linik für Frauenheilkunde und Geburtshilfe, Medizinische Hochschule Hannover, Hannover, Germany; DZentrum

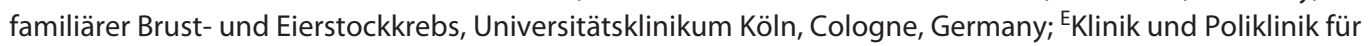
Geburtshilfe und Frauengesundheit der Johannes-Gutenberg-Universität Mainz, Mainz, Germany; ${ }^{\text {FNationales }}$ Centrum für Tumorerkrankungen, Universitätsklinikum und Deutsches Krebsforschungszentrum, Heidelberg, Germany; ${ }^{G}$ Klinik für Gynäkologie und Geburtshilfe, Diakonissen Krankenhaus Speyer, Speyer, Germany; ${ }^{\mathrm{H} S e k t i o n}$ Gynäkopathologie, Pathologisches Institut, Universitätsklinikum Heidelberg, Heidelberg, Germany; 'Jlinik für 
Frauenheilkunde und Geburtshilfe, Universitätsklinikum Frankfurt, Frankfurt, Germany; ${ }^{\mathrm{K}}$ Klinik für Frauenheilkunde, Geburtshilfe und Reproduktionsmedizin, Universitätsklinikum des Saarlandes, Homburg/Saar, Germany; ${ }^{\text {LKlinik }}$ für Gynäkologie und Geburtsmedizin, Universitätsklinikum Aachen, Aachen, Germany; ${ }^{M}$ Universitätsfrauenklinik,

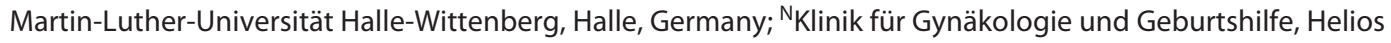
Klinikum Berlin-Buch, Berlin, Germany; ${ }^{\circ}$ Klinik und Poliklinik für Gynäkologie, Universitätsklinikum Hamburg-

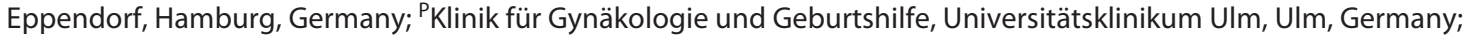
QKlinik für Gynäkologie und gynäkologische Onkologie, Agaplesion Markus Krankenhaus, Frankfurt, Germany

\section{Introduction}

The Breast Committee of the Arbeitsgemeinschaft Gynäkologische Onkologie (German Gynecological Oncology Group, AGO) presents the 2021 update of the evidence-based recommendations for the diagnosis and treatment of patients with early breast cancer (EBC) and metastatic breast cancer. This paper captures the update of EBC while the topics of metastatic breast cancer will be updated by Thill et al. The full version of the updated slide set including annotated speeches of each chapter is available online (www.ago-online.de/ago-kommissionen/ kommission-mamma) in English and German [1]. In addition, a version for patients is also available at www.agoonline.de.

The AGO Breast Committee as an interdisciplinary team consists of specialists from gynecological oncology pathology, diagnostic radiology, medical oncology, and radiation oncology with a special focus on breast cancer. This update was performed according to a documented algorithm, by thoroughly reviewing and scoring chapter by chapter the most recent and relevant publications for their scientific validity (Oxford level of evidence [LoE], www.cebm.net) [2] and clinical relevance (AGO grades of recommendation $[\mathrm{GR}]$ ) (Table 1).

\section{Options for Primary Prevention and Lifestyle Factors}

Individual risk factors can be classified into nonmodifiable and modifiable lifestyle factors. Currently, there is good evidence that changes in some modifiable risk factors could substantially decrease individual breast cancer risk.

Relevant lifestyle factors such as obesity, alcohol consumption (LoE $2 \mathrm{a} / \mathrm{B} / \mathrm{AGO}+$ ), physical inactivity, fibercontaining foods, smoking, and exposition to ionizing radiation are well known. Adherence to normal body weight (BMI $18.5-25 \mathrm{~kg} / \mathrm{m}^{2}$ ) as a preventive factor for the development of breast cancer is well investigated particularly for postmenopausal women ( $\mathrm{LoE} 2 \mathrm{a} / \mathrm{B} / \mathrm{AGO}++$ ). For bariatric surgery, there is initial evidence for a reduction of breast cancer risk [3]. A Mediterranean diet including extra virgin olive oil (LoE 2b/B/AGO+), nuts ( $\mathrm{LoE} 2 \mathrm{~b} / \mathrm{B} /$ $\mathrm{AGO}+)(>10 \mathrm{~g} /$ day $)$, and reduced consumption of fat $(\mathrm{LoE} 2 \mathrm{a} / \mathrm{B} / \mathrm{AGO}+)$ and red meat may decrease the inci- dence of breast cancer. For other factors such as supplementation of vitamin D3, vegetarian or vegan diet, vegetables, fruits, or phytoestrogens there are yet insufficient or contradictory data regarding the reduction of breast cancer incidence. In contrast, physical exercise (metabolic equivalents to $3-5 \mathrm{~h}$ of moderate-pace walking per week) has been demonstrated to be efficient in reducing breast cancer risk ( $\mathrm{LoE} 2 \mathrm{a} / \mathrm{B} / \mathrm{AGO}++$ ).

Avoidance of hormone replacement therapy (especially estrogen/progestin combination regimens) in postmenopausal women may reduce breast cancer risk (LoE 1b/A/AGO+). Oral contraceptives do not increase the probability of death from breast cancer (LoE 1a).

Regarding chemopreventive agents other than endocrine therapy, the effect of acetylsalicylic acid [4], bisphosphonates [5], and statins has been evaluated. Some encouraging results suggest that acetylsalicylic acid use might reduce breast cancer risk, particularly regarding hormone receptor (HR)-positive or in situ breast tumors, in postmenopausal women ( $\mathrm{LoE} 4 \mathrm{D} / \mathrm{D} / \mathrm{AGO}+/-$ ). Bisphosphonates are rated $\mathrm{LoE} 2 \mathrm{~b} / \mathrm{B} / \mathrm{AGO}+/$ - for primary prevention of breast cancer. No risk-reducing effect on breast cancer risk was shown for statins.

\section{Breast Cancer Risk and Prevention}

The AGO Mamma still recommends genetic counseling and testing based on individual and family history. General testing of all breast cancer patients is not recommended as expansion of testing criteria would result only in a slightly higher detection of BRCA1/2 mutations in about $0.7 \%$ but also in a higher detection of other mutations with no evidence-based clinical action [6], increasing the risk of overtreatment. However, there is evidence to suggest that the PARP inhibitor olaparib is effective in PALB2 mutation carriers as well as in patients with somatic BRCA1/2 mutation [7]. New evidence with gene mutation analysis in 113,000 women proved that mutations in BRCA1/2 and PALB2 were associated with high breast cancer risk (LoE 1b/A/AGO++) and ATM, BARD1, CHEK2, RAD 51C, and RAD 51D with moderate breast cancer risk (LoE 1b/B/AGO+) [8]. PALB2 mutation resulted in a lifetime risk for breast cancer almost as high as BRCA2 mutation. Interestingly, the relevance of prostate cancer screening in BRCA2 mutation carriers 
Table 1. AGO grades of recommendation

\begin{tabular}{ll}
\hline++ & $\begin{array}{l}\text { This investigation or therapeutic intervention is highly beneficial for patients, can be recommended without } \\
\text { restrictions, and should be performed }\end{array}$ \\
\hline+ & This investigation or therapeutic intervention is of limited benefit for patients and can be performed \\
$+/-$ & $\begin{array}{l}\text { This investigation or therapeutic intervention has not shown benefit for patients and may be performed only in } \\
\text { individual cases; according to current knowledge a general recommendation cannot be given }\end{array}$ \\
\hline- & This investigation or therapeutic intervention can be of disadvantage for patients and might not be performed \\
\hline- & $\begin{array}{l}\text { This investigation or therapeutic intervention is of clear disadvantage for patients and should be avoided or omitted in } \\
\text { any case }\end{array}$ \\
\hline
\end{tabular}

is unknown and currently investigated in the Impact Trial.

There is still controversy as to the role of breast-conserving surgery (BCS) and mastectomy for BRCA1/2 mutation carriers. Overall, no randomized controlled trial has yet been published. However, one prospectively collected clinical cohort demonstrated that contralateral breast cancer risk was higher for mutation carriers $(24.4 \%$ for BRCA 1 carriers, $20 \%$ for BRCA 2 carriers, and $9 \%$ for noncarriers), but, interestingly, the ipsilateral in-breast recurrence risk was lower $(8.7 \%$ for BRCA1, $14.1 \%$ for BRCA2, and 20\% for noncarriers) [9]. No trial showed a difference in disease-free survival (DFS) according to surgical method [10]. Breast-conserving therapy was not associated with adverse short- or long-term survival outcomes. Therefore, breast-conserving therapy should be offered as an option to BRCA mutation carriers (LoE $2 \mathrm{a} / \mathrm{B} / \mathrm{AGO}+$ ) provided proper preoperative counseling (LoE 5/D/AGO++).

\section{Breast Cancer Diagnostics}

In asymptomatic women, screening mammography (MG) is recommended for women 50-69 years of age (LoE 1a/A/AGO++). For women aged from 40 to 44 screening is not recommended ( $\mathrm{LoE} 1 \mathrm{~b} / \mathrm{B} / \mathrm{AGO}-$ ), and from 45 to 49 individual shared decision-making is recommended and clear indication is necessary (LoE 1a/B/ AGO+). Above 75 years of age screening can be offered to women in good health with a life expectancy of 10 years or longer (LoE 4/C/AGO+/-) [11].

Breast density is a known risk factor for breast cancer development and decreased MG sensitivity. Nevertheless, neither use of hand-held US nor automated wholebreast US can be recommended as a sole modality for screening (LoE 3a/C/AGO-) [11]. Using digital breast tomosynthesis the recall and biopsy rates were low (LoE $1 \mathrm{a} / \mathrm{B} / \mathrm{AGO}+$ ) [12]. Synthetic 2D image reconstruction of the $3 \mathrm{D}$ dataset can significantly reduce radiation dose and is highly recommended ( $\operatorname{LoE} 2 \mathrm{a} / \mathrm{B} / \mathrm{AGO}++$ ). Nevertheless, it is very important to use the complete dataset for diagnosis and provide it for the subsequent treatment [13]. In a recent randomized controlled trial, MRI in the extremely dense breast screening group with negative MG showed a significantly reduced interval cancer rate at the cost of slightly increased false-positive cases (LoE $\mathrm{bb} / \mathrm{B} / \mathrm{AGO}+$ ) [14].

For patients with breast symptoms, clinical examination ( $\mathrm{LoE} 3 \mathrm{~b} / \mathrm{B} / \mathrm{AGO}++)$, $\mathrm{MG}$ ( $\mathrm{LoE} 1 \mathrm{~b} / \mathrm{A} / \mathrm{AGO}++$ ), digital breast tomosynthesis ( $\mathrm{LoE} 2 \mathrm{~b} / \mathrm{B} / \mathrm{AGO}+$ ) or contrastenhanced MG (LoE 2a/B/AGO+), US (LoE 2b/B/ AGO++), and minimally invasive biopsies (LoE 1c/A/ AGO++) should be performed [15].

As part of surgical planning, MRI can be helpful for patients with a reduced sensitivity of MG and US, nipple involvement, lobular invasive cancer, suspicion of multilocular disease, and/or high risk (LoE 1b/B/AGO+), provided that MRI-guided vacuum-assisted biopsy access is available in-house or among cooperating partners [16]. Second-look US is recommended in cases of lesions detected by MRI only.

In patients with clinically and/or sonographically suspicious axillary lymph nodes, core needle biopsy is recommended (LoE 2b/B/AGO++). If biopsy reveals lymph node involvement prior to neoadjuvant therapy, a clip should be inserted in the lymph node after biopsy to allow targeted axillary dissection (TAD) at the time of surgery.

Staging is recommended for candidates scheduled for (neo)adjuvant chemotherapy including CT (chest/abdomen) and bone scans ( $\mathrm{LoE} 2 \mathrm{~b} / \mathrm{B} / \mathrm{AGO}+$ ). PET-CT should be reserved for individual cases with high-stage (III) cancer (LoE 2b/B/AGO+/-).

\section{Pathology}

Established immune markers still preserve their relevance for clinical decision-making in breast cancer treatment with even extended meanings. Estrogen receptor 
(ER) level should not only be categorized in positive or negative. Low ER levels $\leq 10 \%$ of labeled cells needs to be handled differently (LoE 1a/A/AGO++). Tumors with low ER levels are more similar to triple-negative breast cancer (TNBC) than to luminal tumors in terms of their gene expression profiles and frequency of BRCA1/2 germline mutations. Different thresholds to define this subgroup have been applied with $\leq 10 \%$ being the most widely used [17]. Another relevant marker is Ki-67. Ki-67 response (i.e., Ki-67 $\leq 10 \%$ ) after short-term endocrine therapy before surgery can be used to assess endocrine responsiveness (LoE $1 \mathrm{~b} / \mathrm{A} / \mathrm{AGO}+$ ), based on the POETIC [18] and the ADAPT trial results [19].

Recently, it has been shown that in neoadjuvant endocrine therapy (NET) the drop of Ki-67 levels might identify responders after short-term endocrine preoperative therapy (LoE 1b/B/AGO+) [20]. The addition of a novel immune marker like the checkpoint inhibitor atezolizumab or pembrolizumab to chemotherapy showed first promising results regarding pathological complete response (pCR) [21-23, 47].

\section{Lesions of Uncertain Malignant Potential (B3)}

Lesions of uncertain malignant potential (B3) are usually detected by core or vacuum-assisted biopsy in asymptomatic women. The risk of developing invasive cancer associated with B3 lesions can be categorized according to the type of lesion (atypical ductal hyperplasia, flat epithelial atypia, lobular intraepithelial neoplasia, papilloma, radial scar) in addition to clinical and pathological factors. The indication for complete surgical excision of B3 lesions is to exclude any upstaging of more severe precursor lesions (ductal carcinoma in situ [DCIS]) or invasive lesions.

Atypical ductal hyperplasia has a particularly high risk of being associated with breast cancer when combined with BIRADS IV/V and high breast tissue volume. In fact, atypical ductal hyperplasia on core biopsy may represent inadequately sampled DCIS.

In cases of biopsy of classical lobular intraepithelial neoplasia, open excision can be avoided if no discordant imaging, especially no focal lesion, is present [24]. In contrast, high-risk variants of lobular neoplasia, which include pleomorphic and florid lobular carcinoma in situ, are recommended for open biopsy and preferably complete excision.

The diagnosis of solitary or multiple papillomas on core biopsy might be associated with an increased risk of $30 \%$ (with atypia) for an invasive carcinoma or DCIS [25].

A radial scar may mimic carcinoma mammographically because of its stellate appearance. Radial sclerosing lesions are only rarely associated with atypia or DCIS.
When radial scar is associated with atypia (such as flat epithelial atypia, atypical ductal hyperplasia, or classical lobular intraepithelial neoplasia), management can be similar to atypia alone [26].

Medical prevention (e.g., low-dose tamoxifen [LoE $2 \mathrm{~b} / \mathrm{B} / \mathrm{AGO}+/-]$ ) for lesions with uncertain biological behavior may be performed only in individual cases [27].

\section{Prognostic and Predictive Factors}

Locoregional tumor burden together with tumor biology are the major prognostic drivers and the key determinants of therapy decisions in EBC. In luminal EBC, clinical algorithms such as Predict (https://breast.predict.nhs. uk) can be used to estimate prognosis (LoE $1 \mathrm{~b} / \mathrm{A} / \mathrm{AGO}+$ ). For lobular EBC, tumor size, nodal status, and lymphovascular invasion constitute a point-based risk score that can help to identify high-risk disease [28] (LoE 2b/B/AGO+/-). Histological type, however, should not be used as a sole criterion for chemotherapy decision-making (AGO-).

Gene expression assays (LoE 1b/A: Oncotype DX, MammaPrint; LoE 2b/B: EndoPredict, Prosigna) can be used in luminal EBC with 0-3 involved lymph nodes for indicating the use of chemotherapy if the use of routine prognostic factors is not conclusive (AGO+). The decision to omit chemotherapy needs to be based on the respective evidence for the test used. In premenopausal patients, different cutoff values or different thresholds for omitting chemotherapy may need to be applied compared to postmenopausal patients. The results should be discussed with the patients not just in terms of prognosis, but also in terms of absolute gain by adjuvant chemotherapy for DFS and overall survival (OS), including shortand long-term side effects and toxicities.

\section{Ductal Carcinoma in situ}

DCIS accounts for approximately $20 \%$ of all breast cancers in a screening population. MG is the main tool used for diagnosis of DCIS. Breast MRI may be helpful for assessment of the extension and surgical planning of DCIS ( $\mathrm{LoE} 1 \mathrm{~b} / \mathrm{B} / \mathrm{AGO}+/-$ ), but can lead to over- and underestimations of the extension of the DCIS as it represents an extremely heterogeneous group of lesions with variable potential for progression to invasive disease [29]. Complete surgical excision is the standard of care (LoE $1 \mathrm{a} / \mathrm{A} / \mathrm{AGO}++$ ). $\mathrm{BCS}$ is recommended. Almost all guidelines recommend clear margins of $2 \mathrm{~mm}$ for pure DCIS. Sentinel lymph node biopsy might be recommended in rare cases when the surgical procedure is not allowing a sentinel lymph node in case of an upstaging into invasive cancer (i.e., cases of mastectomy, LoE 3b/B/AGO+). 
Radiotherapy is recommended after BCS of DCIS $(\operatorname{LoE} 1 \mathrm{a} / \mathrm{A} / \mathrm{AGO}++)$. Patients should be informed that the absolute (individual) benefit of radiotherapy depends on the individual risk of local recurrence and that available data do not impact survival. In the multicenter, randomized, unblinded BIG 3-07/TROG 07.01 trial, among 1,608 patients hypofractionated whole-breast irradiation presented a HR of 0.94 (95\% CI 0.51-1.74) for local recurrence-free survival and a HR of 0.79 (95\% CI 0.48 1.32) for DFS. By this, conventional fractionated radiotherapy (50 Gy in 25 fractions) (LoE 1a/A/AGO+) or hypofractionated radiotherapy (40-42.5 Gy in 15-16 fractions) are equal options (LoE 1a/A/AGO+) [30]. A boost should only be considered on an individual basis in case of further risk factors ( $\mathrm{LoE} 1 \mathrm{ba} / \mathrm{B} / \mathrm{AGO}+/-$ ). Partial breast irradiation can be considered in cases aged $\geq 50$ years, DCIS $\leq 3 \mathrm{~cm}, \mathrm{G} 1-2, \mathrm{R} 0(\geq 5 \mathrm{~mm})$ and unifocal/unicentric DCIS (LoE 1b/B/AGO+) [31].

Regarding systemic treatment, patients should be informed that adjuvant endocrine treatment has no impact on survival (LoE 1a), but may have a small effect on ipsilateral invasive and DCIS recurrences and on contralateral invasive and noninvasive cancer (LoE 1a). The ongoing discussion whether tamoxifen or anastrozole is more effective was answered by current results of the IBIS-II DCIS trial [32]. After a median follow-up of 11.6 years, there was no difference in breast cancer recurrences (HR 0.89 [95\% CI 0.69-1.16], $p=0.401$ ), but more endometrial (OR 0.17, $p=0.0086$ ) and ovarian cancers (OR 0.13, $p=0.022)$ with tamoxifen and more strokes (OR 3.10, $p=0.021$ ) and transient ischemic attacks (OR 3.10, $p=$ 0.021 ) with anastrozole. By this, both therapies may be considered on an individual basis depending on risk factors, side effects, and patient preference ( $\mathrm{AGO}+/-)$.

\section{Breast Cancer Surgery under Oncological Aspects}

Surgery is part of the multidisciplinary therapeutic approach in EBC. Avoidance of a significant delay of 4 weeks or more in cancer treatment is recommended (AGO+) because of its strong prognostic influence. Wireless intraoperative US localization may serve as an excellent method for tumor detection in BCS (LoE $2 b / B /$ AGO++) [33].

For breast surgery "no ink on tumor" remains the accepted standard for clear margins for all patients (provided that all suspicious lesions according to preoperative imaging are resected $[\mathrm{LoE} 2 \mathrm{a} / \mathrm{A} / \mathrm{AGO}++])$. $\mathrm{BCS}$ is also an option for patients with multifocal and multicentric disease when $\mathrm{R} 0$ resection is confirmed (LoE $2 \mathrm{~b} / \mathrm{B} / \mathrm{AGO}+$ ). Sentinel lymph node excision (SLNE) is the standard of care staging procedure of the ipsilateral axilla in patients with invasive disease and unsuspected nodes (cN0) (LoE
1b/A/AGO++). Suspicious lymph nodes should be evaluated by core needle biopsy and clip placement. This is mainly due to the American College of Surgeons Oncology Group (ACOSOG) Z0011 trial, confirmed by 10 -year follow-up [34], and the AMAROS trial [35] as well as confirming studies with no differences in locoregional control, DFS, or OS.

Following neoadjuvant therapy SLNE should be performed after neoadjuvant chemotherapy (NACT) as it reduces the rate of axillary lymph node dissection (ALND) (ycN0 after $\mathrm{cNO}$ ) and axillary remission provides additional prognostic information ( $\mathrm{LoE} 2 \mathrm{~b} / \mathrm{B} / \mathrm{AGO}++$ ). In patients with a clinically negative axilla $(\mathrm{cN} 0)$ before NACT and tumor-infiltrated sentinel lymph node after NACT (including micrometastases), a full ALND should be performed (LoE 2bB/AGO+) [36].

For patients who initially presented with (core needle biopsy-proven) positive axillary lymph nodes $(\mathrm{pN}+)$ and who converted to ycN0 after NACT, the accuracy of SLNE is lower than in the adjuvant setting [37]. Since unselected axillary sampling is not indicated and ALND may be harmful, TAD offers an alternative in these patients (LoE $2 \mathrm{bB} / \mathrm{AGO}+$ ). TAD implies the combination of SLNE and removal of the core needle biopsy-positive target lymph node (TLNE) marked with a clip, coil, seed, or tattoo. Caudle et al. [38] described a significant reduction in falsenegative rate from $10.1 \%$ with SLNE alone to $4.2 \%$ with TLNE alone, and $1.4 \%$ in case of combination of SLNE and TLNE (TAD). The impact of TAD on DFS is still unknown. In case of residual tumor burden (ypN1) after TAD, ALND is recommended (AGO++); in case of only residual isolated tumor cells, the therapeutic consequence is still unclear and has to be specified in accordance with the results of ongoing studies (e.g., AXSANA trial).

\section{Oncoplastic and Reconstructive Surgery}

Oncoplastic surgery is an essential component in the treatment strategy for breast cancer patients [39]. It is defined as the use of simultaneous reconstructive techniques during breast cancer surgery offering an optimal outcome optimizing quality of life without any compromises towards oncological safety. Oncoplastic surgery focuses on optimized scar positioning, adequate soft tissue shaping, the choice of a suitable reconstruction procedure, and reconstruction of the contralateral breast in order to achieve symmetry. Valid evidence is lacking for the majority of important questions. For implant-based reconstruction, pre- and subpectoral implant placement with or without additional devices (either synthetic or autologous like acelluar dermal matrices) can be performed. Participation in studies to evaluate these procedures should be supported [40]. 
Perioperative systemic antibiotic prophylaxis for implant-based reconstruction is recommended to be performed not longer than $24 \mathrm{~h}(\operatorname{LoE} 2 \mathrm{a} / \mathrm{B} / \mathrm{AGO}+)$, and topical antibiotics/antiseptics should be used frequently as surgical site infection can be decreased significantly when compared to no topical antibiotics (LoE 2a/B/AGO+); moreover, it reduces the rate of capsular contraction [41].

Regarding prevention of capsular contraction, there is good evidence for textured implants (LoE 1a/A/AGO+) and the use of acellular dermal matrices ( $\operatorname{LoE} 2 \mathrm{a} / \mathrm{B} /$ $\mathrm{AGO}+$ ) [42] and synthetic meshes (LoE 3a/C/AGO+) when compared to nothing. Povidone-iodine has become an option again ( $\mathrm{LoE} 2 \mathrm{a} / \mathrm{B} / \mathrm{AGO}+/-)$. Use of leukotriene antagonists (LoE $2 \mathrm{a} / \mathrm{B} / \mathrm{AGO}-$ ) still has limited data regarding their long-term toxicity; no benefit is seen when breast massage is performed ( $\mathrm{LoE} 3 \mathrm{a} / \mathrm{C} / \mathrm{AGO}-$ ). In cases of presence of capsular contraction, capsulectomy and capsulotomy have old but consistent data $(\mathrm{LoE} 3 \mathrm{~b} / \mathrm{C} /$ $\mathrm{AGO}+$ ). If using textured implants or performing capsulectomy/capsulotomy, one has to be aware of breast implant-associated anaplastic large-cell lymphoma that represents a rare malignant disease after implantation of a breast implant, which usually occurs with textured implants.

Therapy of persistent seroma after implant-based reconstruction is lacking robust data. Evacuation of seroma and reinsertion of drainage can be performed and revision surgery with capsulectomy or implant removal is recommended as ultima ratio ( $\mathrm{LoE} 5 / \mathrm{D} / \mathrm{AGO}+$ ). There is no consensus for the duration of drains, but the consistent data are in favor of drain removal at $<30 \mathrm{~mL} / 24 \mathrm{~h}$ (LoE 2b/B/AGO+) [43].

\section{Neoadjuvant Chemotherapy}

If chemotherapy is indicated in patients with EBC, NACT should be preferred. For patients with increased risk of recurrence, dose-dense chemotherapy schedules are recommended, including weekly taxane regimens $(\mathrm{AGO}++)$. Based on current data, a higher $\mathrm{pCR}$ rate and improved DFS can be achieved by use of nab-paclitaxel compared to solvent-based paclitaxel $(\mathrm{HR}+, \mathrm{TNBC})(\mathrm{LoE}$ 1b/B/AGO+) [33, 44-46]. In patients with HER2-positive tumors, anthracycline- and taxane-based or anthracycline-free regimen with carboplatin (both $\mathrm{AGO}++$ ) and trastuzumab (in patients with $\mathrm{N}^{+}$plus pertuzumab $[\mathrm{AGO}++])$ are recommended. In TNBC, dose-dense chemotherapy with anthracyclines including weekly taxanes is the current treatment standard. The addition of platinum is possible, irrespective of BRCA mutation status $(\mathrm{AGO}+)$. Due to significantly increased pCR rates in two neoadjuvant trials, the use of neoadjuvant systemic therapy (NAST) in combination with immune checkpoint in- hibitors including pembrolizumab (Keynote 522 trial) [47] or atezolizumab (IMpassion031 trial) [48] independent from PDL1 status is a new option preferably within clinical trials (LoE $1 \mathrm{~b} / \mathrm{B} / \mathrm{AGO}+/-)$.

\section{Neoadjuvant Endocrine Therapy}

NET is suitable for patients who are inoperable or not able or willing to undergo chemotherapy. Selection of endocrine treatment should be based on the menopausal status and given for at least 4-6 months. NET for 2-4 weeks might be used for prognostic evaluation in oder to predict the efficacy of endocrine treatment by the course of Ki-67 changes.

\section{Post-Neadjuvant Therapy Options - AGO}

\section{Recommendations}

For patients with HR-positive EBC, endocrine therapy according to menopausal status is the standard of care. In the monarchE trial (abemaciclib), in contrast to the PALLAS and PENELOPE-B study (both with palbociclib), the addition of abemaciclib to standard endocrine treatment resulted in an improved 2-year invasive disease-free survival (IDFS) with the caveat of a short follow-up of 19 months. Currently, this option should only be offered within clinical trials (only LoE 2b/B/AGO+/-) [49-51].

Capecitabine is recommended in patients with TNBC and no pCR (LoE 2b/B/AGO+). Patients should be encouraged to participate in clinical trials evaluating experimental postneoadjuvant therapies (AGO+).

Patients who did not achieve pCR should receive 14 cycles of T-DM1 after NAST (LoE 1b/B/AGO+). Based on the results of the ExteNET trial showing a significantly improved DFS rate, escalation of HER2-targeted therapy with neratinib in addition to standard endocrine therapy can be offered to HR-positive patients who have received the last trastuzumab dose within 12 months [52] ( $\mathrm{LoE} 2 \mathrm{~b} / \mathrm{B} / \mathrm{AGO}+/-)$.

In patients with pCR after optimal NAST, continuation of the initiated anti-HER2 therapy is recommended up to completion of 1 year. In patients with pCR and low risk of recurrence, de-escalation to trastuzumab monotherapy is recommended ( $\mathrm{LoE} 2 \mathrm{a} / \mathrm{C} / \mathrm{AGO}++$ ).

\section{Adjuvant Cytotoxic and Targeted Therapy}

Adjuvant anthracycline- and taxane-based chemotherapy reduces breast cancer mortality by approximately one-third, depending on the absolute risk of recurrence [53].

Very recently, a patient-level meta-analysis demonstrated that increasing the dose intensity of chemotherapy by more frequent administration or sequential scheduling moderately improved the 10-year risk of recur- 
rence and death from breast cancer [54]. Therefore, dose-dense chemotherapy (LoE 1a/A/AGO++) instead of conventionally dosed anthracycline- and taxane-based chemotherapy (q3w) (LoE 1/A/AGO+) should be the preferred treatment option. In patients with high risk of recurrence (i.e., $\geq 4$ involved axillary lymph nodes), dosedense and dose-intensified chemotherapy demonstrated superior survival compared with a conventional schedule, especially in high-risk HR-positive patients [55]. Most strikingly, OS was improved with an absolute difference of $10 \%$ after 10 years of follow-up (LoE 1/A/ $\mathrm{AGO}++$ ).

As shown in a meta-analysis, only patients with TNBC and non-pCR after optimal NAST might have a benefit from the addition of capecitabine (LoE 1aa/A/AGO+). Thus, general use in TNBC cannot be recommended (LoE 1aa/A/AGO-) [56]. In TNBC, the question of adding carboplatin as a fourth substance has still not been finally clarified with regard to an OS advantage [57]. However, if an anthracycline-free therapy is chosen, a taxane/platinum combination should be used here (LoE $1 \mathrm{~b} / \mathrm{B} / \mathrm{AGO}+$ ) [58]. In patients with reduced left ventricular ejection fraction, anthracycline-free therapy with docetaxel/cyclophosphamide ( $\mathrm{LoE} 1 \mathrm{~b} / \mathrm{B} / \mathrm{AGO}+$ ) might be an option, while other regimes like weekly paclitaxel (LoE 1b/B/AGO+/-) or CMF (LoE 1a/A/AGO+/-) may not be sufficiently effective. In patients with TNBC tumors and negative lymph nodes, the AGO recommends adjuvant chemotherapy for tumors of 5-10 $\mathrm{mm}$, while for tumors $<0.5 \mathrm{~cm}$ there is no indication for adjuvant chemotherapy (LoE 2b/B/AGO-).

In patients with HER2-positive EBC, anti-HER2 therapy with trastuzumab is highly recommended (LoE 1a/A/AGO++). Trastuzumab might be either combined with an anthracycline- and taxane-based chemotherapy (LoE 1a/A/AGO++) or an anthracycline-free regimen like carboplatin/docetaxel ( $\mathrm{LoE} 1 \mathrm{~b} / \mathrm{A} / \mathrm{AGO}++$ ). In patients with HER2-positive node-negative EBC with a maximum diameter of $2 \mathrm{~cm}$, trastuzumab might be combined with weekly paclitaxel ( $\mathrm{LoE} 2 \mathrm{~b} / \mathrm{B} / \mathrm{AGO}+$ ). Based on the updated follow-up of the APT trial, patients with node-negative EBC treated with this de-escalating regimen had an excellent 7-year IDFS of 93\%. The updated analysis of the APHINITY trial support adjuvant pertuzumab in addition to trastuzumab and chemotherapy only in patients with node-positive disease with HER2positive $\mathrm{EBC}$ ( $\mathrm{LoE} 1 \mathrm{ba} / \mathrm{B} / \mathrm{AGO}+$ ). At a median follow-up of 74.1 months IDFS in node-positive patients was $87.9 \%$ for trastuzumab and pertuzumab versus $83.4 \%$ for trastuzumab. In the node-negative cohort, no additional clinical benefit was evident for the dual blockade (LoE 1ba/B/ $\mathrm{AGO}+/-)$.

For extended adjuvant treatment (EAT), the tyrosine kinase inhibitor neratinib in combination with standard endocrine treatment for 12 months may be an option for HR-positive patients who have completed 1 year of trastuzumab-based therapy (LoE 1b/B/AGO+).

\section{Adjuvant Endocrine Therapy}

Endocrine therapy is indicated in all patients with HRpositive $\mathrm{EBC}$ (LoE 1/A/AGO++). A meta-analysis of the German Breast Group of several neoadjuvant trials suggests that tumors with low HR expression ( $\geq 1-9 \%)$ are biologically similar to TNBC. Thus, omitting endocrine therapy may be an option in cases with very low expression of ER and progesterone receptor (PR) (LoE 1/A/AGO++) [59]. In case of ER-/PR+ (>10\%), immunohistochemical re-evaluation of ER should be performed. False positivity for PR should be excluded [60]. A treatment duration of 5 years remains the standard of care. EAT might be indicated in patients with increased risk of relapse, such as GIII or nodepositive disease at presentation.

\section{Premenopausal Patients}

The SOFT and TEXT trials are providing the most relevant evidence for treatment recommendations in premenopausal patients [61]. Patients with a low risk of recurrence might be treated with tamoxifen (LoE 1a/A/ $\mathrm{AGO}++$ ), patients with an intermediate recurrence risk should be offered ovarian function suppression in addition to tamoxifen ( $\mathrm{LoE} 2 \mathrm{~b} / \mathrm{C} / \mathrm{AGO}++$ ), and in patients with a high risk of recurrence risk the use of aromatase inhibitors (AIs) and ovarian function suppression (for 5 years) (LoE 1b/B/AGO+) might be the best option. All other statements from 2020 are still valid.

\section{Postmenopausal Patients}

Interestingly the recommendations from 2020 have not been changed. With regard to the adjuvant use of CDK4/6 inhibitors, three studies have been published (PENELOPE-B, PALLAS, and monarchE) [62-64]. But none of these drugs have a label in the adjuvant setting yet.

\section{EAT in Premenopausal Women}

Tamoxifen can be extended for up to 10 years (LoE 1a/A/AGO++). EAT with 5 years of tamoxifen should also be offered to those patients with ovarian suppression and tamoxifen or an AI for their initial treatment (LoE $5 / \mathrm{D} / \mathrm{AGO}+$ ). If the patient is confirmed as being postmenopausal within the first 5 years, endocrine therapy can be continued after 5 years of tamoxifen with 2.5-5 years of letrozole (LoE 1b/B/AGO+).

\section{EAT in Postmenopausal Women}

After 5 years of tamoxifen, extended therapy with 5 years of tamoxifen is still an option ( $\operatorname{LoE} 1 \mathrm{a} / \mathrm{A} / \mathrm{AGO}+$ ), 
but switching to an AI for 2-5 years should be preferred $(\mathrm{LoE} 1 \mathrm{a} / \mathrm{A} / \mathrm{AGO}++)$. If patients received an AI (upfront or switch), patients at higher risk should be offered 2-5 additional years of $\mathrm{AI}(\mathrm{LoE}$ 1b/B/AGO+).

\section{Adjuvant Radiotherapy}

Moderately hypofractionated whole-breast radiotherapy remains the standard of care for the majority of patients after BCS (LoE 1a/A/AGO++). Ultra-hypofractionated whole-breast irradiation in five fractions over 1 or 5 weeks according to the FAST [65] and FAST-Forward [66] trials may be used in selected cases $(\mathrm{LoE} 1 \mathrm{~b} / \mathrm{B} /$ $\mathrm{AGO}+/-)$. A tumor bed boost is routinely recommended in premenopausal patients ( $\mathrm{LoE} 1 \mathrm{~b} / \mathrm{B} / \mathrm{AGO}++$ ) and should be used in a risk-adapted manner in postmenopausal patients (LoE $2 \mathrm{~b} / \mathrm{B} / \mathrm{AGO}+$ ). If using conventionally fractionated whole-breast radiotherapy, the use of a simultaneous integrated boost is feasible, as shown by two recent randomized controlled trials (LoE $1 \mathrm{~b} / \mathrm{B} / \mathrm{AGO}+$ ) $[67,68]$. Partial breast irradiation with interstitial brachytherapy, intensity-modulated radiotherapy over one-anda-half weeks, or 3D conformal radiotherapy over 3 weeks are viable options for patients with early-stage, low-risk breast cancer (LoE 1a/A/AGO+). Intraoperative radiotherapy such as partial breast irradiation should preferentially be used in patients aged $>70$ years $(\mathrm{LoE} 1 \mathrm{~b} / \mathrm{A} / \mathrm{AGO}+$; $\mathrm{LoE} 1 \mathrm{~b} / \mathrm{A} / \mathrm{AGO}+/$ - for patients $>50$ years). Recommendations regarding post-mastectomy radiotherapy and regional nodal irradiation to the supra-/infraclavicular and the internal mammary lymphatics remain unchanged. Radiotherapy to the axilla (level I/II in addition to wholebreast or post-mastectomy radiotherapy) should be performed in patients who do not fulfil the ACOSOG Z0011 criteria and did not undergo ALND ( $\mathrm{LoE} 1 \mathrm{~b} / \mathrm{B} / \mathrm{AGO}++$ ). After ALND, radiotherapy to the axilla should only be performed in case of macroscopic residual disease (LoE 5/D/AGO++). After NACT, patients with ypN1mic(sn/ $\mathrm{TAD})$ or $\mathrm{ypN}+(\mathrm{sn} / \mathrm{TAD})$ who did not undergo ALND should receive radiotherapy to the axilla $(\mathrm{LoE} 5 / \mathrm{D} / \mathrm{AGO}+)$. Patients with clinically positive lymph nodes who convert to ypN0(sn/TAD) after NACT may receive additional radiotherapy to the axilla ( $\mathrm{LoE} 5 / \mathrm{D} / \mathrm{AGO}+/-$ ). If CDK4/6 inhibitors are used in the adjuvant setting, treatment may be given sequentially with adjuvant radiotherapy, as in the relevant phase III trials ( $\mathrm{LoE} 4 / \mathrm{C} / \mathrm{AGO}+/-$ ).

\section{Breast Cancer: Special Situations}

While tamoxifen remains the standard for endocrine treatment of male breast cancer, some evidence also exists for use of AIs and fulvestrant. There are very limited data supporting the use of CDK4/6 inhibitors among male patients with breast cancer [69]. However, the FDA has recently expanded the approved indications to include men. Based on this, the AGO recommends the use of CDK4/6 inhibitors for male patients with advanced/metastatic breast cancer ( $\mathrm{LoE} 2 \mathrm{~b} / \mathrm{B} / \mathrm{AGO}+$ ).

The indications for mastectomy after NACT remain unchanged: positive margins after repeated excisions ( $\mathrm{LoE} 3 \mathrm{~b} / \mathrm{C} / \mathrm{AGO}++$ ), lack of feasibility of radiotherapy (LoE 5/D/AGO++), and presence of inflammatory breast cancer (with no more than clinical complete response) $(\mathrm{LoE} 2 \mathrm{~b} / \mathrm{C} / \mathrm{AGO}+/-)$ [70].

Phyllodes tumors are classified as benign, borderline, and malignant, with varying risk of local recurrence. Recently, it has been shown that narrow margins for phyllodes tumors are not associated with an increased risk of local recurrence, and it was proposed that a negative margin may not be necessary for benign phyllodes tumors [71]. Therefore, the AGO has agreed to revise the minimal resection margins required for borderline and malignant phyllodes tumors, and a resection margin of $1 \mathrm{~mm}$ is now considered sufficient ( $\mathrm{LoE} 2 \mathrm{~b} / \mathrm{B} / \mathrm{AGO}++$ ).

Metaplastic breast carcinoma must be distinguished into the commonly observed high-grade metaplastic carcinoma and the rare forms of metaplastic carcinoma with uncertain malignant potential (fibromatous-like and adenosquamous carcinoma). Typically, metaplastic breast carcinomas are malignancies with triple-negative immune phenotype, but their prognostic and therapeutic implications differ from usual TNBC [72]. They tend to be rather chemoresistant, and this must be considered for planning adjuvant therapy or NACT. Operative therapy, axillary staging, and adjuvant radiotherapy should be performed according to the standard ( $\mathrm{LoE} 4 / \mathrm{C} / \mathrm{AGO}++$ ) for high-grade tumors. However, for low-grade - fibromatous-like and adenosquamous - metaplastic carcinomas, no benefit of adjuvant (LoE 4/C/AGO-) or neoadjuvant (LoE 4/C/AGO-) chemotherapy can be expected, because these are considered to be tumors of uncertain malignant potential [73].

\section{Complementary Therapy and Survivorship}

Recently published studies and review articles underline the effects of physical exercise (endurance training three times a week in combination with workout exercises two times a week) on quality of life, cardiorespiratory fitness, physical performance, sleep, pain, depression, lymphedema, and fatigue ( $\mathrm{LoE} 1 \mathrm{a} / \mathrm{A} / \mathrm{AGO}++$ ). Evidence is growing that mind-body interventions (including cognitive therapies, behavioral therapies, relaxation techniques, and meditation) improve quality of life among breast cancer patients, and therefore clinical guidelines 
have begun to include recommendations. A systemic review and meta-analysis of 19 randomized controlled trials $(n=2,806)$ revealed evidence that mind-body interventions are efficacious for reducing fear of cancer recurrence, although further investigations are recommended to analyze the optimal integration of mind-body practices (LoE 1a/A/AGO+).

Acupuncture can improve chemotherapy-induced nausea and vomiting, cancer pain, fatigue, menopause syndrome, anxiety and depression, as well as AI-induced arthralgia (AGO+).

\section{Gynecological Issues in Breast Cancer Patients and Contraception}

Systemic hormone replacement therapy to alleviate menopausal symptoms is contraindicated in breast cancer patients (LoE $1 \mathrm{~b} / \mathrm{B} / \mathrm{AGO}-$ ), while topical vaginal application of low-dose estriol may be used for urogenital symptoms ( $\mathrm{LoE} 4 / \mathrm{D} / \mathrm{AGO}+/-$ ). Hot flushes may be treated with serotonin reuptake inhibitors (i.e., venlafaxine) ( $\operatorname{LoE} 1 \mathrm{a} / \mathrm{A} / \mathrm{AGO}+$ ). A recent study found that 2.5 or $5.0 \mathrm{mg}$ oxybutynin twice a day for 6 weeks was an effective treatment option for women with hot flushes [74] (LoE 1b/A/AGO+/-). Homeopathy and phytotherapy had no effect on hot flushes in large randomized trials compared with placebo in breast cancer survivors (LoE 1b/B/AGO-) [75]; interestingly, in these studies a substantial effect was observed also in the control arm ("placebo effect"). Sleep disturbances might be treated with melatonin (LoE 2b/C/AGO+).

Physical exercise has positive effects on menopausal symptoms and, to a lesser degree, on the sexuality of patients experiencing treatment-induced menopause (LoE 1a/A/AGO++) [76]. Cognitive behavioral therapy is effective in alleviating treatment-induced menopausal symptoms ( $\mathrm{LoE} 1 \mathrm{~b} / \mathrm{B} / \mathrm{AGO}++$ ). Mind-body medicine results in a moderate improvement in hot flushes scores, joint pain, fatigue, and sleep ( $\mathrm{LoE} 1 \mathrm{~b} / \mathrm{B} / \mathrm{AGO}+$ ). There are contradictory data about the effect of acupuncture on hot flushes, depression, and sleep disturbances, but it can be used to treat AI-induced joint pain (LoE 1b/B/AGO+) [77].

Fertility counseling on fertility preservation (https:// fertiprotekt.com) should be offered to all patients who wish to retain their fertility (AGO++). Application of gonadotropin-releasing hormone analogs $>2$ weeks prior chemotherapy has shown an improved rate of recovery of ovarian function after 2 years (LoE $1 \mathrm{a} / \mathrm{B} / \mathrm{AGO}+)$ and might have a moderate effect on preservation of fertility (LoE 2a/B/AGO+/-). Low anti-Müllerian hormone levels seem to be indicative of reduced ovarian reserve in chemotherapy-treated breast cancer patients (LoE 1b/B/ $\mathrm{AGO}+$ ).
Hormone-free contraceptive methods are the first choice for patients with breast cancer.

Sexual complaints are common in breast cancer patients and should be assessed. Screening tools may help physicians to address sexual health issues (LoE $4 / \mathrm{C} /$ AGO+). Nonhormonal lubricants and moisturizers are the primary treatment for vaginal dryness and dyspareunia (LoE $1 \mathrm{~b} / \mathrm{B} / \mathrm{AGO}+)$. Microablative fractionated laser or vaginal YAG/erbium laser may be an option for some patients to alleviate genital atrophy ( $\mathrm{LoE} 2 \mathrm{a} / \mathrm{A} / \mathrm{AGO}+/-)$ [78].

\section{Breast Cancer: Supportive Care and Side Effect Management}

Optimal side effect management and supportive care are major contributors to the overall risk/benefit balance associated with oncological therapies. This chapter of the AGO recommendations details aspects that are particularly relevant for the treatment of breast cancer patients and is based on the most recent version of the S3 guidelines [79] as well as other international guidelines such as those of the ESMO wherever available.

Chemotherapy can lead to reactivation of hepatitis $B$ in carriers [80]. Before start of chemotherapy, screening for hepatitis $B$ (HBsAG, anti-HBC) should therefore be performed in all patients $(\mathrm{LoE} 2 \mathrm{c} / \mathrm{AGO}+)$. If one of the tests is positive, HBV DNA needs to be determined. In case of HBV DNA detection, virostatic therapy needs to be initiated and chemotherapy interrupted $(\mathrm{AGO}++)$.

The essential drug management for antiemetic therapy has been revised (https://www.mascc.org). For patients in the acute and as well in the delayed emetic highrisk group, olanzapine may be offered on days $1-4$, particularly if nausea is a concern. As sedation and weight gain are side effects, a dose reduction from 10 to $5 \mathrm{mg} /$ day is a valid option $[81,82]$.

Chemotherapy-induced peripheral neuropathy is a common toxicity following taxane or subsequent T-DM1 therapy with an incidence of up to $50 \%$ grade 1-2 and up to $20 \%$ grade 3 and 4 . Thus, besides continuing measures for neuropathy prevention such as tight surgical gloves and compression stockings ( $\mathrm{LoE} 2 \mathrm{~b} / \mathrm{B} /$ $\mathrm{AGO}+$ ), cooling gloves and stockings (LoE 2b/B/ $\mathrm{AGO}+/-$ ) and tactile stimulation (LoE 5/D/AGO+) are very important. While drug-based prevention and treatment options are limited (AGO+/-), non-drug-based therapy might be an option $(\mathrm{AGO}+)$ with functional treatment $(\operatorname{LoE} 2 \mathrm{a} / \mathrm{C})$, physiotherapy $(\operatorname{LoE} 5 / \mathrm{D})$, and acupuncture (LoE $2 \mathrm{~b} / \mathrm{B})$. 


\section{Follow-Up of Breast Cancer}

Less intensive follow-up for patients with DCIS (clinical examination all 6 months) versus patients with invasive breast cancer (all 3 months) is recommended.

Still, the rationale of breast cancer follow-up is the early detection of curable breast cancer events (LoE 1a/B/ $\mathrm{AGO}++)$. Early detection of symptomatic metastases is desirable ( $\mathrm{LoE} \mathrm{3b/C/AGO+);} \mathrm{however,} \mathrm{with} \mathrm{regard} \mathrm{to} \mathrm{the}$ early detection of asymptomatic metastases (LoE 1a/A/ AGO-), data are inconsistent and, most importantly, do not suggest a survival benefit.

Beyond improvement of survival, additional issues like improvement of quality of life and physical performance as well as the reduction and early detection of treatment-related side effects are important concerns in this matter (LoE 2b/B/AGO+). We added recommendations on cardiologic workup (echocardiography, BNP measurement in selected cases) in patients treated by anthracyclines/anti-HER2 agents in the adjuvant situation 12 and 60 months after therapy completion according to international guidelines [83].

In addition, re-evaluation of current adjuvant therapies (including re-evaluation of menopausal status and change and/or addition of ovarian suppression in highrisk premenopausal patients with chemotherapy-induced amenorrhea) and the assessment or improvement of treatment adherence is an essential part of follow-up care (LoE $2 \mathrm{~b} / \mathrm{B} / \mathrm{AGO}++)$. Thus, it should be pointed out that every patient has the right to obtain a second opinion ( $\mathrm{LoE} 2 \mathrm{c} / \mathrm{B} /$ $\mathrm{AGO}++$ ); genetic counseling should be offered if indicated, as should hormone replacement therapy, prophylactic surgery, and breast reconstruction ( $\mathrm{LoE} 2 \mathrm{c} / \mathrm{C} / \mathrm{AGO}+$ ). Lifestyle modifications and interventions with regard to comorbidities are further important aspects of follow-up.

Most importantly, follow-up examinations of asymptomatic patients in routine situations should not include tumor marker measurements or imaging of any kind. For the detection of curable events, physical and self-examination with MG and adjunctive US as well monitoring of treatment toxicity (e.g., of endocrine therapy) are recommended. Follow-up of male breast cancer patients should follow the same procedures as in female breast cancer patients (LoE 5/D/AGO+). Unfortunately, there are still no data that would support tailoring breast cancer follow-up according to molecular subtype.

In case of increased risk such as age $<50$ years, HR negativity, and decreased diagnostic accessibility $\mathrm{C} / \mathrm{D}$ in MG and US, MRI should be considered [84].

In this context, screening for secondary malignancies according to guidelines is meaningful. Patients and physicians should be aware of increased risk of hematologic malignancies after chemotherapy and lung cancer after radiotherapy to the breast or chest wall. Further, a DXA scan at baseline and a repeat scan according to individual risk in women with premature ovarian failure or in women on AI therapy are recommended [85].

\section{Health Literacy and Communication}

The options for healthy people and patients in cancer prevention and therapy are constantly increasing. At the same time, a change has taken place in the healthcare system, which strengthens the patients' right of self-determination and embodied in law the informed and shared decision-making process between patients and their doctors, who should no longer make decisions on prevention and treatment concepts alone.

Healthy people as well as patients should be instructed and involved as "experts in their own affairs" during the process of preventing and treating cancer. The main focus is on enabling a self-determined decision on the basis of a sufficient heathy competence $(\mathrm{AGO}+)$ and improving shared decision-making, which depends on successful doctor-patient communication.

\section{Health Literacy}

Despite a huge media presence of expert content, it seemed to be difficult for the majority of patients to distinguish between what is really important and how to make the right decisions for coping with illness (health literacy). According to a current survey from 2017, half of all Germans have insufficient or clearly limited health literacy. As a result, numerous initiatives and offers were launched to improve health literacy (Alliance for Health Literacy, National Action Plan Health Literacy). They focus on the special form of doctor-patient relationship and are based on an overarching set of values: respect for the right of self-determination of the individual, the principle of non-harm, care, and equality.

\section{Communication}

Good communication skills are a medical core competence and the basis for a trusting doctor-patient relationship. This in turn has an important influence on the understanding of the disease as well as on cooperation in diagnosis, treatment, and rehabilitation, and thus on the success of treatment. "Talking medicine" is becoming increasingly important in the healthcare system (remuneration) and is offered across sectors as a part of training and continuing education programs for all healthcare professionals. Qualified training measures can help to promote communicative skills (AGO+).

\section{Shared Decision-Making and Patient Decision Aids}

Successful communication and the development of a trustful doctor-patient relationship is an important cor- 
nerstone for patient participation in the shared decisionmaking process. The use of decision support in the physician-patient communication (AGO+) will (a) improve knowledge, information, and risk perception about treatment options, (b) reduce the decision conflict, (c) increase the feeling about clarity of personal values, (d) encourage an active role in decision-making, and (e) improve the match between the chosen option and the patient's values.

\section{Conflict of Interest Statement}

N. Ditsch: MSD, Novartis, Pfizer, Roche, AstraZeneca, Teva, Mentor, MCI. M. Untch: Presentations and travel grants, all paid to his institution by Abbvie, Amgen GmbH München, AstraZeneca, BMS, Celgene GmbH München, Daiichi Sankyo, Eisai GmbH München, Janssen Cilag, Johnson \& Johnson, Lilly Deutschland, Lilly Int., MSD, Mundipharma, Myriad Genetics GmbH Zürich, Odonate, Pfizer GmbH Berlin, PUMA Biotechnology, Riemser, Roche Pharma AG Grenzach-Wyhlen, Sanofi Aventis Deutschland GmbH, Sividon Diagnostics Köln, Teva Pharmaceuticals Ind. Ltd. Berlin. C. Kolberg-Liedtke: Advisory boards: Phaon Scientific, Novartis, Pfizer, SurgVision, Carl Zeiss Meditec, Amgen, Onkowissen. Lectures: Roche, Novartis, Pfizer, Lilly, Genomic Health, Amgen, AstraZeneca, Riemser, Carl Zeiss Meditec, Teva, Theraclion Janssen-Cilag, GSK, LIV Pharma, Theramex. Travel expenses: Carl Zeiss Meditec, LIV Pharma, Novartis, Amgen, Pfizer, Daiichi Sankyo. D. Krug: MSD. M. Friedrich: Roche, Pfizer, AstraZeneca, Novartis. W. Janni: Research grants and/or honoraria: Sanofi-Aventis, Novartis, Roche, Pfizer, AstraZeneca, Chugai, GSK, Eisai, Celgene, Lilly, Janssen, Menarini. V. Müller: Speaker honoraria: Amgen, AstraZeneca, Daiichi Sankyo, Eisai, Pfizer, MSD, Novartis, Roche, Teva, Seattle Genetics. Consultancy honoraria: Genomic Health, Hexal, Roche, Pierre Fabre, Amgen, ClinSol, Novartis, MSD, Daiichi Sankyo, Eisai, Lilly, Tesaro, Nektar. Institutional research support: Novartis, Roche, Seattle Genetics, Genentech. U.-S. Albert: Lectures and/or consulting: Medexo GmbH, Institut für Versicherungsmedizin, Pfizer. M. Banys-Paluchowski: Advisory board: Eisai. Lectures: AstraZeneca. Study support: Mammotome, EndoMag, MeritMedical. I. Bauerfeind: No conflicts of interest. J.-U. Blohmer: Honoraria: Amgen, AstraZeneca, Genomic Health, MSD Oncology, Myriad Genetics, Novartis, Pfizer, Roche, Sonoscape. Travel and accommodation expenses: Pfizer, Roche. W. Budach: No conflicts of interest. P. Dall: Advisory boards: Olympus, Roche, Novartis, Tesaro. Congress support: Roche. Lectures: Amgen, Roche. E.M. Fallenberg: GE Healthcare, Siemens, ECR, EUSOBI, ESOR, KCR, DFG. P.A. Fasching: Grants: Novartis, BioNTech, Cepheid. Personal fees: Novartis, Roche, Pfizer, Celgene, Daiichi Sankyo, AstraZeneca, MSD, Myelo Therapeutics, Macrogenics, Eisai, Puma, Lilly. T. Fehm: AstraZeneca, Celgene, Pfizer, Novartis, Roche, Teva, Daiichi Sankyo. B. Gerber: No conflicts of interest. O. Gluz: Lecture and consulting fees: Celgene, Roche, Genomic Health, Amgen, Pfizer, Novartis, Lilly, Nanostring, Eisai, MSD. Travel expenses: Celgene, Roche, Daiichi Sankyo. N. Harbeck: Lecture and/or consulting fees: Agendia, Amgen, AstraZeneca, BMS, Celgene, Daiichi Sankyo, Genomic Health, Lilly, MSD, Novartis, Odonate, Pierre Fabre, Pfizer, Roche, Sandoz/Hexal, Seattle Genetics. Minority share holder: Westdeutsche Studiengruppe. J. Heil: No conflicts of interest. J. Huober: Research support: Celgene, Novartis, Hexal. Lectures: Lilly, Novartis, Roche, Pfizer, AstraZeneca, MSD, Celgene, Eisai, Abbvie. Consulting: Lilly, Novartis, Roche, Pfizer, Hexal, AstraZeneca, MSD, Celgene, Abbvie. Travel expenses:
Roche, Pfizer, Novartis, Celgene, Daiichi Sankyo. C. Jackisch: Advisory boards: Amgen, AstraZeneca, Novartis, Pierre Fabre, Exact Sciences, Roche, Lilly, Pfizer. Travel grants: Roche, Novartis, Pfizer, Exact Sciences, Amgen. Lectures: Amgen, AstraZeneca, Daiichi Sankyo, Novartis, Pierre Fabre, Exact Sciences, Roche, Lilly, Pfizer. H.-H. Kreipe: Reimbursement for attending symposia: Ventana. Other expenses (advisory boards, lectures): Amgen, AstraZeneca, Genomic Health, Lilly, Roche Pharma. T. Kühn: Celgene, Roche, Pfizer. S. Kümmel: Roche, Genentech, Novartis, AstraZeneca, Amgen, Celgene, SOMATEX, Daiichi Sankyo, Puma Biotechnology, pfm medical, Pfizer, MSD Oncology. S. Loibl: Advisory boards/lectures: Abbvie, Amgen, AstraZeneca, Celgene, Novartis, Pfizer, Roche, Seattle Genetics, PriME/Medscape, Daiichi Sankyo, Lilly, Samsung, Eirgenix, BMS, Puma, MSD, Merck, Pierre Fabre. D. Lüftner: Advisory boards/oral presentations: Amgen, AstraZeneca, GSK, Eli Lilly, L'Oréal, MSD, Mundipharma, Mylan, Novartis, Pfizer, Roche, Teva. M.P. Lux: Advisory boards, lectures, travel support: Lilly, Pfizer, Roche, MSD, Hexal, Novartis, AstraZeneca, Eisai, medac, Genomic Health. N. Maass: No conflicts of interest. C. Mundhenke: Not specified. U. Nitz: Not specified. T.-W. Park-Simon: Advisory role or expert testimony and lecture honoraria: Roche, AstraZeneca, Tesaro, Pfizer, Daiichi Sankyo, Lilly, MSD. Participation in clinical trials: Roche, AstraZeneca, Tesaro, Pfizer, Daiichi Sankyo, Lilly, MSD, Novartis, Seattle Genetics. Other financial relationships such as travel: Roche, AstraZeneca, Tesaro, Pfizer, Lilly, MSD, Novartis. T. Reimer: Grants: German Cancer Aid, Else Kröner-Fresenius-Stiftung. Personal fees. Pfizer, Roche, Novartis, AstraZeneca outside the submitted work. K. Rhiem: AstraZeneca, Tesaro, Pfizer, Roche. A. Rody: Roche, Pfizer, Novartis, Celgene, Novartis, Genomic Health/Exact Sciences, AstraZeneca, Eisai, MSD, Hexal, Amgen. M. Schmidt: Personal fees: AstraZeneca, Roche, Lilly, SeaGen, MSD, Eisai. Grants: Pierre Fabre, Pantarhei Bioscience, BioNTech, Genentech outside the submitted work. Patent issued for EP 2390370 B1 and EP 2951317 B1. A. Schneeweiss: Grants: Celgene, Roche, Abbvie, Molecular Partner. Personal fees: Roche, AstraZeneca, Celgene, Pfizer, Novartis, MSD, Tesaro, Lilly. F. Schütz: Amgen, AstraZeneca, Lilly, Hexal, MSD, Novartis, Pfizer, Roche, Onkozert, Eickeler Kongressorganisation. H.-P. Sinn: No conflicts of interest related to the submitted manuscript. C. Solbach: Travel, accommodations: Roche, Novartis, AstraZeneca, Amgen, Celgene, Hexal, Daiichi Sankyo, Dialog Service GmbH, Lilly, Pfizer, MSD Oncology, ESAI, Gedon Richter, Mylan, Tesaro. E.-F. Solomayer: Roche, AstraZeneca, Pfizer, Amgen, Celgene, Tesaro, AstraZeneca, Storz, Erbe, Gedeon Richter, Eisai, Medac, MSD, Vifor, Teva, Ethikon. E. Stickeler: Counseling: Novartis, Pfizer, AstraZeneca, Roche, Tesoro. Fees: Novartis, Pfizer, AstraZeneca, Roche. C. Thomssen: Advisory boards and lectures: Amgen, AstraZeneca, Celgene, Daiichi Sankyo, Eisai, Lilly, MSD, Mylan, Nanostring, Novartis, Pfizer, Pierre Fabre, Puma, Roche, Vifor. Research support (by discount prizes): American Diagnostica, Affymetrix, Nanostring. I. Witzel: Not specified. A. Wöckel: Amgen, AstraZeneca, Aurikamed, Celgene, Eisai, Lilly, Novartis, Pfizer, Roche, Tesaro, Sirtex, MSD, Genomic Health, Pierre Fabre, Clovis. M. Thill: Advisory boards: Amgen, AstraZeneca, Celgene, ClearCut, Clovis, Daiichi Sankyo, Exact Sciences, Lilly, MSD, Neodynamics, Novartis, Pfizer, pfm medical, Pierre Fabre, Roche, Tesaro. Manuscript support: Amgen, Celgene, Roche. Travel expenses: Amgen, Art Tempi, AstraZeneca, Celgene, Clovis, Connect Medica, Daiichi Sankyo, Exact Sciences, Hexal, I-Med Institute, Lilly, MCI, MSD, Novartis, Pfizer, pfm medical, Roche, Tesaro. Congress fees: Amgen, AstraZeneca, Celgene, Daiichi Sankyo, Hexal, Novartis, Pfizer, Roche. Lectures: Amgen, Art Tempi, AstraZeneca, Celgene, Clovis, Connect Medica, Exact Sciences, Hexal, I-Med Institute, Lilly, MCI, MSD, Novartis, OnkoLive, Pfizer, pfm medical, Roche. Trial funding: Exact Sciences. 


\section{Funding Sources}

This article did not receive any funding.

\section{Author Contributions}

The paper was written by all of the authors.

\section{References}

1 Empfehlungen Gynäkologische Onkologie Kommission Mamma, 2021. www.ago-online.org.

2 www.cebm.net.

3 Ishihara BP, Farah D, Fonseca MCM, Nazario A. The risk of developing breast, ovarian, and endometrial cancer in obese women submitted to bariatric surgery: a meta-analysis. Surg Obes Relat Dis. 2020 Oct;16(10): 1596-602.

4 Cao Y, Tan A. Aspirin might reduce the incidence of breast cancer: an updated meta-analysis of 38 observational studies. Medicine (Baltimore). 2020 Sep;99(38):e21917.

5 Peng R, Liang X, Zhang G, Yao Y, Chen Z, Pan $\mathrm{X}$, et al. Association use of bisphosphonates with risk of breast cancer: a meta-analysis. Biomed Res Int. 2020 Oct;2020:5606573.

6 Yadav S, Hu C, Hart SN, Boddicker N, Polley $\mathrm{EC}, \mathrm{Na}$ J, et al. Evaluation of germline genetic testing criteria in a hospital-based series of women with breast cancer. J Clin Oncol. 2020; 38:1409-18.

7 Tung NM, Robson ME, Ventz S, Santa-Maria CA, Nanda R, Marcom PK, et al. TBCRC 048: Phase II study of olaparib for metastatic breast cancer and mutations in homologous recombination-related genes. J Clin Oncol. 2020 Dec;38(36):4274-82.

8 Breast Cancer Association Consortium, Dorling L, Carvalho S, Allen J, González-Neira A, Luccarini C, Wahlström C, et al. Breast cancer risk genes - association analysis in more than 113,000 Women. N Engl J Med. 2021 Feb; 384(5):428-39.

9 Co M, Liu T, Leung J, Li CH, Tse T, Wong M, et al. Breast conserving surgery for BRCA mutation carriers - a systematic review. Clin Breast Cancer. 2020 Jun;20(3):e244-50.

10 Yoon KH, Chae S, Kang E, Shin HC, Kim JH, $\mathrm{Kim}$ IA, et al. Contralateral breast cancer and ipsilateral breast tumor recurrence in BRCA1/2 carriers and non-carriers at highrisk of hereditary breast cancer. J Breast Cancer. 2019 Sep;22(4):587-98.

11 https://healthcare-quality.jrc.ec.europa.eu/ european-breast-cancer-guidelines/screening-ages-and-frequencies.

12 Alabousi M, Wadera A, Kashif Al-Ghita M, Al-Ghetaa RK, Salameh JP, Pozdnyakov A, et al. Performance of digital breast tomosynthesis, synthetic mammography and digital mammography in breast cancer screening: a systematic review and meta-analysis. J Natl Cancer Inst. 2020 doi: 10.1093/jnci/djaa205. Online ahead of print.

13 Phi XA, Tagliafico A, Houssami N, Greuter MJW, de Bock GH. Digital breast tomosynthesis for breast cancer screening and diagnosis in women with dense breasts - a systematic review and meta-analysis. BMC Cancer. 2018 Apr;18(1):380.

14 Bakker MF, de Lange SV, Pijnappel RM, Mann RM, Peeters PHM, Monninkhof EM, et al. Supplemental MRI screening for women with extremely dense breast tissue. N Engl J Med. 2019 Nov;381(22):2091-2102.

15 Dromain C, Vietti-Violi N, Meuwly JY. Angiomammography: a review of current evidences. Diagn Interv Imaging. 2019 Oct; 100(10):593-605.

16 Mariscotti G, Durando M, Tagliafico A, Campanino PP, Bosco D, Casella C, et al. Preoperative breast cancer staging with multi-modality imaging and surgical outcomes. Eur J Radiol. 2020 Jan;122:108766.

17 Deyarmin B, Kane JL, Valente AL, van Laar R, Gallagher C, Shriver CD, et al. Effect of ASCO/ CAP guidelines for determining ER Status on molecular subtype. Ann Surg Oncol. 2013 Jan; 20(1):87-93.

18 Smith I, Robertson J, Kilburn L, Wilcox M, Evans A, Holcombe C, et al. Long-term outcome and prognostic value of Ki67 after perioperative endocrine therapy in postmenopausal women with hormone-sensitive early breast cancer (POETIC): an open-label, multicentre, parallelgroup, randomised, phase 3 trial. Lancet Oncol. 2020 Nov;21(11):1443-54.

19 Nitz U, Gluz O, Kreipe HH, Christgen M, Kuemmel S, Baehner FL, et al. The run-in phase of the prospective WSG-ADAPT HR+/HER2trial demonstrates the feasibility of a study design combining static and dynamic biomarker assessments for individualized therapy in early breast cancer. Ther Adv Med Oncol. 2020 Nov; 12:1758835920973130.

20 Dowsett M, Ellis MJ, Dixon JM, Gluz O, Robertson J, Kates R, et al. Evidence-based guidelines for managing patients with primary ER+ HER2- breast cancer deferred from surgery due to the COVID-19 pandemic. NPJ Breast Cancer. 2020 Jun;6:21.

21 Schmid P, Adams S, Rugo HS, Schneeweiss A, Barrios $\mathrm{CH}$, Iwata $\mathrm{H}$, et al. Atezolizumab and Nab-paclitaxel in advanced triple-negative breast cancer. N Engl J Med. 2018;379(22): 2108-21.

22 Noske A, Ammann JU, Wagner DC, Denkert C, Lebeau A, Sinn P, et al. A multicentre analytical comparison study of inter-reader and inter-assay agreement of four programmed death-ligand 1 immunohistochemistry assays for scoring in triple-negative breast cancer. Histopathology. 2021 Mar;78(4):567-77.

23 Harbeck N, Zhang H, Barrios CH, Saji S, Jung KH, Hegg R, et al. LBA11 - IMpassion031: Results from a phase III study of neoadjuvant atezolizumab + chemotherapy in early triplenegative breast cancer (TNBC). Ann Oncol. 2020;31(4):S1142-215.

24 Sinn P, Brucker SY, Budach W, et al. DCIS und Risikoläsionen. In: Leitlinienprogramm Onkologie der AWMF, DKG und DKH, editor. Interdisziplinäre S3-Leitlinie für die Diagnostik, Therapie und Nachsorge des Mammakarzinoms. 2017; p. 79-89.
25 Khan S, Diaz A, Archer KJ, Lehman RR, Mullins T, Cardenosa G, et al. Papillary lesions of the breast: to excise or observe? Breast J. 2018 May;24(3):350-5.

26 Rageth CJ, O’Flynn EAM, Pinker K, KubikHuch RA, Mundinger A, Decker T, et al. Second International Consensus Conference on lesions of uncertain malignant potential in the breast (B3 lesions). Breast Cancer Res Treat. 2019 Apr;174(2):279-96.

27 DeCensi A, Puntoni M, Guerrieri-Gonzaga A Caviglia S, Avino F, Cortesi L, et al. Randomized placebo controlled trial of low-dose tamoxifen to prevent local and contralateral recurrence in breast intraepithelial neoplasia. J Clin Oncol. 2019 Jul;37(19):1629-37.

28 De Nonneville A, Jauffret C, Gonçalves A, Classe JM, Cohen M, Reyal F, et al. Adjuvant chemotherapy in lobular carcinoma of the breast: a clinicopathological score identifies high-risk patient with survival benefit. Breast Cancer Res Treat. 2019 Jun;175(2): 379-87.

29 Takada K, Kashiwagi S, Asano Y, Goto W, Morisaki T, Takahashi K, et al. Factors predictive of invasive ductal carcinoma in cases preoperatively diagnosed as ductal carcinoma in situ. BMC Cancer. 2020;20:513.

30 Chua BH, Link E, Kunkler I, Olivotto I, Westenberg AH, Whelan T, et al., Breast International Group (BIG)-aisbl, Trans Tasman Radiation Oncology Group, Scottish Cancer Trials Breast Group, Canadian Cancer Trials Group, European Organization for Research and Treatment of Cancer, International Breast Cancer Study Group, Cancer Trials Ireland. A randomized phase III study of radiation doses and fractionation schedules in non-low risk ductal carcinoma in situ (DCIS) of the breast (BIG 3-07/TROG 07.01). Abstract GS2-04, 2020 San Antonio Breast Cancer Virtual Symposium, December 8-11, 2020, San Antonio, Texas, DOI: 10.1158/1538-7445.SABCS20GS2-04 (published February 2021). 2020.

31 Strnad V, Krug D, Sedlmayer F, Piroth MD, Budach W, Baumann R, et al. Breast Cancer Expert Panel of the German Society of Radiation Oncology (DEGRO). DEGRO practical guideline for partial-breast irradiation. Strahlenther Onkol. 2020 Sep;196(9):74963.

32 Sestak I, Cuzick J, Bonanni B, Bundred B, Levy C, Loibl S, et al. 12 year results of anastrozole versus tamoxifen for the prevention of breast cancer in postmenopausal women with locally excised ductal carcinoma in-situ. Abstract GS2-02, 2020 Virtual San Antonio Breast Cancer Symposium, December 8-11, 2020. 2020.

$33 \mathrm{Hu}$ X, Li S, Jiang Y, Wei W, Ji Y, Li Q, et al. Intraoperative ultrasound-guided lumpectomy versus wire-guided excision for nonpalpable breast cancer. J Int Med Res. 2020 Jan; 48(1):300060519896707. 
34 Giuliano AE, Ballman KV, McCall L, Beitsch PD, Brennan MB, Kelemen PR, et al. Effect of axillary dissection vs no axillary dissection on 10-year overall survival among women with invasive breast cancer and sentinel node metastasis: The ACOSOG Z0011 (Alliance) Randomized Clinical Trial. JAMA. 2017 Sep; 318(10):918-26.

35 Donker M, van Tienhoven G, Straver ME, Meijnen P, van de Velde CJ, Mansel RE, et al. Radiotherapy or surgery of the axilla after a positive sentinel node in breast cancer (EORTC 10981-22023 AMAROS): a randomised, multicentre, open-label, phase 3 non-inferiority trial. Lancet Oncol. 2014; 15(12):1303-10.

36 Moo TA, Edelweiss M, Hajiyeva S, Stempel M, Raiss M, Zabor EC, et al. Is low-volume disease in the sentinel node after neoadjuvant chemotherapy an indication for axillary dissection? Ann Surg Oncol. 2018;25(6):148894.

37 Tee SR, Devane LA, Evoy D, Rothwell J, Geraghty J, Prichard RS, et al. Meta-analysis of sentinel lymph node biopsy after neoadjuvant chemotherapy in patients with initial biopsyproven node-positive breast cancer. $\mathrm{Br}$ Surg36. 2018 Nov; 105(12):1541-52.

38 Caudle AS, Yang WT, Krishnamurthy S, Mittendorf EA, Black DM, Gilcrease MZ, et al. Improved axillary evaluation following neoadjuvant therapy for patients with node-positive breast cancer using selective evaluation of clipped nodes: implementation of targeted axillary dissection. J Clin Oncol. 2016 Apr; 34(10):1072-8

39 Weber WP, Soysal SD, El-Tamer M, Sacchini V, Knauer M, Tausch C, et al. First international consensus conference on standardization of oncoplastic breast conserving surgery. Breast Cancer Res Treat. 2017 Aug;165(1): 139-49.

40 Weber WP, Morrow M, Boniface J, Pusic A, Montagna G, Kappos EA, et al. Knowledge gaps in oncoplastic breast surgery. Lancet Oncol. 2020 Aug;21(8):e375-85.

41 Hai Y, Chong W, Lazar MA. Extended prophylactic antibiotics for mastectomy with immediate breast reconstruction: a meta-analysis. Plast Reconstr Surg Glob Open. 2020 Jan; 8(1):e2613.

42 Hallberg H, Rafnsdottir S, Selvaggi G, Strandell A, Samuelsson O, Stadig I, et al. Benefits and risks with acellular dermal matrix (ADM) and mesh support in immediate breast reconstruction: a systematic review and meta-analysis. J Plast Surg Hand Surg. 2018 Jun;52(3): 130-47.

43 Scomacao I, Cummins A, Roan E, Duraes EFR, Djohan R. The use of surgical site drains in breast reconstruction: a systematic review. J Plast Reconstr Aesthet Surg. 2020 Apr;73(4): 651-62.

44 Untch M, Jackisch C, Schneeweiss A, Schmatloch S, Aktas B, Denkert C, et al. NAB-paclitaxel improves disease-free survival in early breast cancer: GBG 69-GeparSepto. J Clin Oncol. 2019 Sep;37(25):2226-34.

45 Kuemmel S, Gluz O, Christgen M, Potenberg J, Hackmann, von Schumann R, et al. Efficacy of response- and toxicity-guided neoadjuvant chemotherapy in elderly early breast cancer patients: Results of WSG ADAPT elderly subtrial. Cancer Res. 2020;80(4 Suppl 1):abstract P2-16-05.

46 JU Blohmer, Link T, Kümmel S, Untch M, Just M, Fasching PA, et al. Investigating denosumab as an add-on treatment to neoadjuvant chemotherapy and two different nab-paclitaxel schedules in a $2 \times 2$ design in primary breast cancer - first results of the GeparX study. Cancer Res. 2020;80(4 Suppl 1):abstract GS3-01.

47 Schmid P, Cortes J, Pusztai L, McArthur H, Kümmel S, Bergh J, et al.; KEYNOTE-522 Investigators. Pembrolizumab for early triplenegative breast cancer. N Engl J Med. 2020; 382(9):810-21.

48 Mittendorf EA, Zhang $\mathrm{H}$, Barrios $\mathrm{CH}$, Saji S, Jung KH, Hegg R, et al. Neoadjuvant atezolizumab in combination with sequential nabpaclitaxel and anthracycline-based chemotherapy versus placebo and chemotherapy in patients with early-stage triple-negative breast cancer (IMpassion031): a randomised, double-blind, phase 3 trial. Lancet. 2020; 396(10257):1090-100.

49 O'Shaughnessy JA, Johnston S, Harbeck N, Toi M, Im YH, Reinisch M, et al. Primary outcome analysis of invasive disease-free survival for monarchE: abemaciclib combined with adjuvant endocrine therapy for high risk EBC. San Antonio Breast Cancer Symposium. 2020. GS1-01.

50 Mayer EL, Dueck AC, Martin M, Rubovszky G, Burstein HJ, Bellet-Ezquerra M, et al. Palbociclib with adjuvant endocrine therapy in EBC (PALLAS): interim analysis of a multicentre, open-label, randomised, phase 3 study. Lancet Oncol. 2021;22(2):212-22.

51 Loibl S, Marmé F, Martin M, Untch M, Bonnefoi H, Kim SB, et al. Phase III study of palbociclib combined with endocrine therapy (ET) in patients with hormone-receptor-positive $(\mathrm{HR}+)$, HER2-negative primary breast cancer and with high relapse risk after neoadjuvant chemotherapy (NACT): first results from PENELOPE-B. San Antonio Breast Cancer Symposium. 2020. GS1-02.

52 Chan A, Moy B, Mansi J, Ejlertsen B, Holmes FA, Chia S, et al.; ExteNET Study Group. Final efficacy results of neratinib in HER2-positive hormone receptor-positive early-stage breast cancer from the phase III ExteNET trial. Clin Breast Cancer. 2021;21(1):80-91.e7.

53 Early Breast Cancer Trialists' Collaborative Group (EBCTCG); Peto R, Davies C, Godwin J, Gray R, Pan HC, Clarke M, et al. Comparisons between different polychemotherapy regimens for early breast cancer: meta-analyses of long-term outcome among 100,000 women in 123 randomised trials. Lancet. 2012; 379(9814):432-44.

54 Early Breast Cancer Trialists' Collaborative Group (EBCTCG). Increasing the dose intensity of chemotherapy by more frequent administration or sequential scheduling: a patient-level meta-analysis of 37298 women with early breast cancer in 26 randomised trials. Lancet. 2019;393(10179):1440-52.

55 Schneeweiss A, Möbus V, Tesch H, Klare P, Denkert C, Kast K, et al. Survival analysis of the randomized phase III GeparOcto trial comparing neoadjuvant chemotherapy
(NACT) of iddEPC versus weekly paclitaxel, liposomal doxorubicin (plus carboplatin in triple-negative breast cancer, TNBC) $(\mathrm{PM}(\mathrm{Cb}))$ for patients (pts) with high-risk early breast cancer (BC). Ann Oncol. 2020; 31(Suppl 4):S303-4.

56 Wang X, Wang SS, Huang H, Cai L, Zhao L, Peng RJ, et al. Effect of capecitabine maintenance therapy using lower dosage and higher frequency vs observation on disease-free survival among patients with early-stage triplenegative breast cancer who had received standard treatment: the SYSUCC-001 randomized clinical trial. JAMA. 2021 Jan;325(1):50-8.

57 Yu KD, Ye FG, He M, Fan L, Ma D, Mo M, et al. Effect of adjuvant paclitaxel and carboplatin on survival in women with triple-negative breast cancer: a phase 3 randomized clinical trial. JAMA Oncol. 2020 Sep;6(9):1390-6.

58 Gluz O, Nitz U, Liedtke C, Christgen M, Grischke EM, Forstbauer H, et al. Comparison of neoadjuvant Nab-paclitaxel + carboplatin vs Nab-paclitaxel + gemcitabine in triple-negative breast cancer: randomized WSG-ADAPT-TN trial results. J Natl Cancer Inst. 2018 Jun;110(6): 628-37.

59 Villegas S, Lederer B. Similarities between low hormone receptor positive and hormone receptor negative breast cancer: an analysis of 4366 patients from multicenter clinical trials. San Antonio Breast Cancer Symposium. 2018. P2-08-10.

60 Viale G, Regan MM, Maiorano E, Mastropasqua MG, Dell'Orto P, Rasmussen BB, et al. Prognostic and predictive value of centrally reviewed expression of estrogen and progesterone receptors in a randomized trial comparing letrozole and tamoxifen adjuvant therapy for postmenopausal early breast cancer: BIG 1-98. J Clin Oncol. 2007;25(25):3846-52.

61 Francis PA, Pagani O, Fleming GF, Walley BA, Colleoni M, Láng I, et al.; SOFT and TEXT Investigators and the International Breast Cancer Study Group. Tailoring adjuvant endocrine therapy for premenopausal breast cancer. $\mathrm{N}$ Engl J Med. 2018;379:122-37.

62 Mayer EL, Dueck AC, Martin M, Rubovszky G, Burstein HJ, Bellet-Ezquerra M, et al. Palbociclib with adjuvant endocrine therapy in early breast cancer (PALLAS): interim analysis of a multicentre, open-label, randomised, phase 3 study. Lancet Oncol. 2021;22(2):212-22.

63 Loibl S, Marmé F, Martin M, Untch M, Bonnefoi H, Kim S-B, et al. Phase III study of palbociclib combined with endocrine therapy (ET) in patients with hormone-receptor-positive (HR+), HER2-negative primary breast cancer and with high relapse risk after neoadjuvant chemotherapy (NACT): first results from PENELOPE-B. San Antonio Breast Cancer Symposium. 2020. GS1-02.

64 Johnston SRD, Harbeck N, Hegg R, Toi M, Martin M, Shao ZM, et al. Abemaciclib combined with endocrine therapy for the adjuvant treatment of HR+, HER2-, node-positive, high-risk, early breast cancer (monarchE). J Clin Oncol. 2020;38:3987-98.

65 Brunt AM, Haviland JS, Sydenham M, Agrawal RK, Algurafi H, Alhasso A, et al. Ten-year results of FAST: a randomized controlled trial of 5-fraction whole-breast radiotherapy for EBC. J Clin Oncol. 2020 Oct;38(28):3261-72. 
66 Brunt AM, Haviland JS, Wheatley DA, Sydenham MA, Alhasso A, Bloomfield DJ, et al. Hypofractionated breast radiotherapy for 1 week versus 3 weeks (FAST-Forward): 5-year efficacy and late normal tissue effects results from a multicentre, non-inferiority, randomised, phase 3 trial. Lancet. 2020 May;395(10237): 1613-26.

67 Choi KH, Ahn SJ, Jeong JU, Yu M, Kim JH, Jeong BK, et al. Postoperative radiotherapy with intensity-modulated radiation therapy versus 3-dimensional conformal radiotherapy in EBC: a randomized clinical trial of KROG 15-03. Radiother Oncol. 2020 Sep;154:179-86.

68 Hörner-Rieber J, Forster T, Hommertgen A, Haefner MF, Arians N, König L, et al. Intensity modulated radiation therapy (IMRT) with simultaneously integrated boost shortens treatment time and is noninferior to conventional radiation therapy followed by sequential boost in adjuvant breast cancer treatment: results of a large randomized phase III trial (IMRT-MC2 Trial). Int J Radiat Oncol Biol Phys. 2021 Apr; 109(5):1311-24.

69 Wedam S, Fashoyin-Aje L, Bloomquist E, Tang S, Sridhara R, Goldberg KB, et al. FDA Approval Summary: Palbociclib for male patients with metastatic breast cancer. Clin Cancer Res. 2020; 26:1208-12.

70 Spanheimer PM, Murray MP, Zabor EC, Stempel M, Morrow M, Van Zee KJ, et al. Long-term outcomes after surgical treatment of malignant/borderline phyllodes tumors of the breast. Ann Surg Oncol. 2019;26:2136-43.

71 Rosenberger LH, Thomas SM, Nimbkar SN, Hieken TJ, Ludwig KK, Jacobs LK, et al. Contemporary multi-institutional cohort of 550 cases of phyllodes tumors (2007-2017) demonstrates a need for more individualized margin guidelines. J Clin Oncol. 2021;39(3):178-89.
72 Corso G, Frassoni S, Girardi A, De Camilli E, Montagna E, Intra $\mathrm{M}$, et al. Metaplastic breast cancer: prognostic and therapeutic considerations. J Surg Oncol. 2021;123(1):61-70.

73 Rakha EA, Badve S, Eusebi V, Reis-Filho JS, Fox $\mathrm{SB}$, Dabbs DJ, et al. Breast lesions of uncertain malignant nature and limited metastatic potential: proposals to improve their recognition and clinical management. Histopathology. 2016;68: 45-56.

74 Leon-Ferre RA, Novotny PJ, Wolfe EG, Faubion SS, Ruddy KJ, Flora D, et al. Oxybutynin vs placebo for hot flashes in women with or without breast cancer: a randomized, doubleblind clinical trial (ACCRU SC-1603). JNCI Cancer Spectr. 2019;4:pkz088.

75 Heudel PE, van Praagh-Doreau I, Duvert B, Cauvin I, Hardy-Bessard AC, Jacquin JP, et al. Does a homeopathic medicine reduce hot flushes induced by adjuvant endocrine therapy in localized breast cancer patients? A multicenter randomized placebo-controlled phase III trial. Support Care Cancer. 2019;27:187989.

76 Lahart IM, Metsios GS, Nevill AM, Carmichael AR. Physical activity for women with breast cancer after adjuvant therapy. Cochrane Database Syst Rev. 2018;1:CD011292.

77 Hershman DL, Unger JM, Greenlee H, Capodice JL, Lew DL, Darke AK, et al. Effect of acupuncture vs sham acupuncture or waitlist control on joint pain related to aromatase inhibitors among women with early-stage breast cancer: a randomized clinical trial. JAMA. 2018;320:167-76.

78 Athanasiou S, Pitsouni E, Douskos A, Salvatore $\mathrm{S}$, Loutradis D, Grigoriadis T. Intravaginal energy-based devices and sexual health of female cancer survivors: a systematic review and metaanalysis. Lasers Med Sci76. 2020 Feb;35(1):1-11.
79 S3-Leitlinie: Supportive Therapie bei onkologischen PatientInnen - Langversion 1.3, Februar 2020, AWMF Registernummer: 032/054OL. http://leitlinienprogrammonkologie.de/Supportive-Therapie.95.0.html.

80 Liu Z, Jiang L, Liang G, Song E, Jiang W, Zheng $\mathrm{Y}$, et al. Hepatitis B virus reactivation in breast cancer patients undergoing chemotherapy: a review and meta-analysis of prophylaxis management. J Viral Hepat. 2017;24(7):561-72.

81 Hashimoto H, Abe M, Tokuyama O, Mizutani H, Uchitomi Y, Yamaguchi T, et al. Olanzapine $5 \mathrm{mg}$ plus standard antiemetic therapy for the prevention of chemotherapy-induced nausea and vomiting (J-FORCE): a multicenter, randomized, double-blind, placebo-controlled, phase 3 trial. Lancet Oncol. 2020;21(2):242-9.

82 Slimano F, Netzer F, Borget I, Lemare F, Besse B. Olanzapine as antiemetic drug in oncology: a retrospective study in non-responders to standard antiemetic therapy. Int J Clin Pharm. 2018 Oct;40(5):1265-71.

83 Curigliano G, Lenihan D, Fradley M, Ganatra S, Barac A, Blaes A, et al. Management of cardiac disease in cancer patients throughout oncological treatment: ESMO consensus recommendations. Ann Oncol. 2020;31:171-90.

84 Shah C, Ahlawat S, Khan A, Tendulkar RD, Wazer DE, Shah SS, et al. The role of MRI in the follow-up of women undergoing breast-conserving therapy. Am J Clin Oncol. 2016 Jun; 39(3):314-9.

85 Runowicz CD, Leach CR, Henry NL, Henry KS, Mackey HT, Cowens-Alvarado RL, et al. American Cancer Society/American Society of Clinical Oncology breast cancer survivorship care guideline. CA Cancer J Clin. 2016;66:43-73. 